\title{
ПРОСТРАНСТВЕННОЕ МОДЕЛИРОВАНИЕ ЗОН РАСПРОСТРАНЕНИЯ ЭКСТЕРНАЛИЙ ПРОЦЕССОВ КЛАСТЕРИЗАЦИИ НА ТЕРРИТОРИИ РЕГИОНОВ ПОВОЛЖЬЯ
}

\author{
(c) 2021 Напольских Дмитрий Леонидович \\ кандидат экономических наук, доцент кафедры управления и права \\ Поволжский государственный технологический университет, Россия, Йошкар-Ола \\ E-mail: NapolskihDL@yandex.ru
}

\begin{abstract}
Представлен теоретический подход к пространственному моделированию процессов трансформации экономического пространства региона. На основании транспортной доступности выделены следующие пространственные зоны инновационных кластеров: центр кластера и периферия. Выделены центры кластеризации четырёх регионов Поволжья, проанализированны характеристики их экономического пространства.
\end{abstract}

Ключевые слова: экономическое пространство, инновационные кластеры, пространственное моделирование, трансформация экономики.

Введение. Российские макрорегионы, в том числе и Поволжье, отличаются высокой степенью дифференциации с точки зрения экономикогеографического положения, площади территории и структуры регионального экономического пространства [6]. Вместе с тем задачи, закреплённые в Стратегии пространственного развития Российской Федерации, актуализируют задачу повышения эффективности и качества управления трансформацией экономического пространства регионов Поволжья. Необходимость активизации внутренних факторов развития регионов [11], а также повышения связанности и структурированности их экономического пространства формирует научно-практическую задачу поиска новых форм пространственного развития.

В качестве основной формы пространственной организации и развития производства, интегрирующей в условиях цифровизации экономики перечисленные выше объекты экономического пространства, автором рассматривается инновационный кластер [2-4]. Инновационные кластеры представляют собой существенно отличающиеся от остального пространства области, включающие не менее 10 (в случае развитых кластеров более 100) предприятий и организаций. Участники кластера достаточно тесно расположены в пространстве, зачастую территориально срастаются. Связанность, структурированность и неоднородность территории кластера по отношению к окружающему экономическому пространству достигается за счёт сложной конфигурации производственных, научно-технических, кадровых и социальных взаимосвязей его участников [7]. В связи с этим сохраняет актуальность задача формализации модели трансформации экономического пространства российских регионов на основе формирования инновационных кластеров.

Результаты исследования. Кластеризация экономического пространства региона также изменяет циклы жизнедеятельностью населения территории. Пространственные границы влияния эффектов кластеризации на территорию и жизнедеятельность населения можно выделить на основании транспортной доступности относительно ядра кластера или отдельных крупных организаций участников [8]. В частности, на основании транспортной доступности можно выделить следующие пространственные зоны: «Центр кластера» - часовая изохрона относительно предприятий и организаций, формирующих ядро инновационного кластера; «Периферия» - полуторачасовая изохрона относительно предприятий и организаций, формирующих ядро инновационного кластера, либо часовая изохрона относительно отдельных крупных организаций, не входящих в центр кластера.

В ходе исследования также были выделены центры кластеризации Нижегородской области, определены и проанализированные характеристики экономического пространства данного

\footnotetext{
* Работа выполнена в рамках гранта РНФ 19-78-00056 «Кластерная модель развития регионов Поволжья в условиях инновационной экономики»
} 
региона. Ключевым центром инновационной трансформации экономического пространства Нижегородской области является Нижегородский индустриальный инновационный кластер в области автомобилестроения и нефтехимии. Якорные предприятия кластера находятся в городах Нижний Новгород и Дзержинск, также предприятия кластера расположены в следующих населённых пунктах: г. Арзамас, г. Бор, г. Кстово, г. Павлово. Рассмотрим характеристики экономического пространства области, находящегося под непосредственным воздействием экстерналий кластерного развития. В таблице 1 представлены данные о численности населения и площади муниципальных образований, отне- сённых к центру и периферии кластера.

Центром инновационной трансформации экономического пространства Пензенской области являются следующие инновационные кластеры: IT кластер Пензенской области; Зареченский кластер интеграции технологий (КИТ); Инженерно-производственный кластер «Биомед»; Пензенский приборостроительный кластер «Безопасность». Якорные предприятия перечисленных кластеров находятся в городах Пенза и Заречный. В таблице 2 представлены данные о численности населения и площади муниципальных образований, отнесённых к центру и периферии кластеров.

Таблица 1. Муниципальные образования Нижегородской области, территория которых относится к ядру, центру и периферии индустриального инновационного кластера в области автомобилестроения и нефтехимии

\begin{tabular}{|c|c|c|c|c|c|}
\hline Территории & $\begin{array}{c}\text { Население, } \\
\text { чел. }\end{array}$ & $\begin{array}{c}\text { Доля от } \\
\text { населения } \\
\text { региона, \% }\end{array}$ & $\begin{array}{c}\text { Площадь, } \\
\text { км}^{2}\end{array}$ & $\begin{array}{c}\text { Доля от пло- } \\
\text { щади регио- } \\
\text { на, \% }\end{array}$ & $\begin{array}{c}\text { Плотность } \\
\text { населения, } \\
\text { чел./км² }\end{array}$ \\
\hline Нижегородская область, всего & 3202946 & $100,00 \%$ & 76900 & $100,00 \%$ & 41,65 \\
\hline $\begin{array}{l}\text { Экономическое пространство } \\
\text { кластера, всего }\end{array}$ & 2618242 & $81,74 \%$ & 31153 & $40,51 \%$ & 84,04 \\
\hline Ядро кластера, всего & 1510608 & $47,16 \%$ & 831 & $1,08 \%$ & 1817,82 \\
\hline Нижний Новгород & 1271767 & $39,71 \%$ & 410 & $0,53 \%$ & 3101,87 \\
\hline город Дзержинск & 238841 & $7,46 \%$ & 421 & $0,55 \%$ & 567,32 \\
\hline Центр кластера, без ядра & 635477 & $19,84 \%$ & 12170 & $15,83 \%$ & 52,22 \\
\hline город Бор & 118156 & $3,69 \%$ & 3584 & $4,66 \%$ & 32,97 \\
\hline Балахнинский район & 75698 & $2,36 \%$ & 896 & $1,17 \%$ & 84,48 \\
\hline Богородский район & 59357 & $1,85 \%$ & 1459 & $1,90 \%$ & 40,68 \\
\hline Володарский район & 57962 & $1,81 \%$ & 1049 & $1,36 \%$ & 55,25 \\
\hline Городецкий район & 85620 & $2,67 \%$ & 1482 & $1,93 \%$ & 57,77 \\
\hline Дальнеконстантиновский район & 20352 & $0,64 \%$ & 1377 & $1,79 \%$ & 14,78 \\
\hline Кстовский район & 125938 & $3,93 \%$ & 1226 & $1,59 \%$ & 102,72 \\
\hline Павловский район & 92394 & $2,88 \%$ & 1097 & $1,43 \%$ & 84,22 \\
\hline Периферия кластера, всего & 472157 & $14,74 \%$ & 18152 & $23,60 \%$ & 26,01 \\
\hline Арзамас & 103979 & $3,25 \%$ & 41 & $0,05 \%$ & 2536,07 \\
\hline Городской округ Семеновский & 46662 & $1,46 \%$ & 3877 & $5,04 \%$ & 12,04 \\
\hline Городской округ Саров & 96052 & $3,00 \%$ & 232 & $0,30 \%$ & 414,02 \\
\hline Городской округ Первомайск & 17990 & $0,56 \%$ & 1227 & $1,60 \%$ & 14,66 \\
\hline Ардатовский район & 22522 & $0,70 \%$ & 1887 & $2,45 \%$ & 11,94 \\
\hline Арзамасский район & 40248 & $1,26 \%$ & 2010 & $2,61 \%$ & 20,02 \\
\hline Большемурашкинский район & 9353 & $0,29 \%$ & 658 & $0,86 \%$ & 14,21 \\
\hline Вадский район & 13922 & $0,43 \%$ & 742 & $0,96 \%$ & 18,76 \\
\hline Дивеевский район & 14959 & $0,47 \%$ & 844 & $1,10 \%$ & 17,72 \\
\hline Лукояновский район & 28593 & $0,89 \%$ & 1890 & $2,46 \%$ & 15,13 \\
\hline Лысковский район & 37407 & $1,17 \%$ & 2134 & $2,78 \%$ & 17,53 \\
\hline Сосновский район & 17641 & $0,55 \%$ & 1170 & $1,52 \%$ & 15,08 \\
\hline Шатковский район & 22829 & $0,71 \%$ & 1440 & $1,87 \%$ & 15,85 \\
\hline
\end{tabular}


Таблица 2. Муниципальные образования, территория которых относится к ядру, центру и периферии инновационных кластеров Пензенской области

\begin{tabular}{|c|c|c|c|c|c|}
\hline Территории & $\begin{array}{c}\text { Население, } \\
\text { чел. }\end{array}$ & $\begin{array}{c}\text { Доля от } \\
\text { населения } \\
\text { региона,\% }\end{array}$ & Площадь, км² & $\begin{array}{c}\text { Доля от } \\
\text { площади } \\
\text { региона, \% }\end{array}$ & 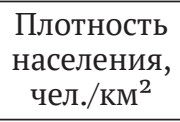 \\
\hline Пензенская область, всего & 1305563 & $100,0 \%$ & 43200 & $100,00 \%$ & 30,2 \\
\hline $\begin{array}{l}\text { Экономическое пространство } \\
\text { кластеров, всего }\end{array}$ & 1154769 & $88,4 \%$ & 29950 & $69,33 \%$ & 38,6 \\
\hline Ядро кластеров, всего & 585802 & $44,9 \%$ & 412 & $0,95 \%$ & 1421,8 \\
\hline город Пенза & 520300 & $39,9 \%$ & 288 & $0,67 \%$ & 1806,6 \\
\hline город Заречный & 65502 & $5,0 \%$ & 124 & $0,29 \%$ & 528,2 \\
\hline Центр кластеров, без ядра & 214519 & $16,4 \%$ & 11840 & $27,41 \%$ & 18,1 \\
\hline Бессоновский район & 47952 & $3,7 \%$ & 1340 & $3,10 \%$ & 35,8 \\
\hline Городищенский район & 47111 & $3,6 \%$ & 2160 & $5,00 \%$ & 21,8 \\
\hline Лунинский район & 17513 & $1,3 \%$ & 1620 & $3,75 \%$ & 10,8 \\
\hline Мокшанский район & 25036 & $1,9 \%$ & 2300 & $5,32 \%$ & 10,9 \\
\hline Пензенский район & 61233 & $4,7 \%$ & 2920 & $6,76 \%$ & 21,0 \\
\hline Шемышейский район & 15674 & $1,2 \%$ & 1500 & $3,47 \%$ & 10,4 \\
\hline Периферия кластеров, всего & 354448 & $27,1 \%$ & 17698 & $40,97 \%$ & 20,0 \\
\hline город Кузнецк & 80497 & $6,2 \%$ & 23 & $0,05 \%$ & 3499,9 \\
\hline Белинский район & 22902 & $1,8 \%$ & 2020 & $4,68 \%$ & 11,3 \\
\hline Иссинский район & 9162 & $0,7 \%$ & 950 & $2,20 \%$ & 9,6 \\
\hline Каменский район & 52928 & $4,1 \%$ & 2170 & $5,02 \%$ & 24,4 \\
\hline Камешкирский район & 10612 & $0,8 \%$ & 1200 & $2,78 \%$ & 8,8 \\
\hline Колышлейский район & 22380 & $1,7 \%$ & 1660 & $3,84 \%$ & 13,5 \\
\hline Кузнецкий район & 35865 & $2,7 \%$ & 2100 & $4,86 \%$ & 17,1 \\
\hline Малосердобинский район & 8146 & $0,6 \%$ & 990 & $2,29 \%$ & 8,2 \\
\hline Нижнеломовский район & 37003 & $2,8 \%$ & 1850 & $4,28 \%$ & 20,0 \\
\hline Пачелмский район & 13969 & $1,1 \%$ & 1410 & $3,26 \%$ & 9,9 \\
\hline Сердобский район & 46612 & $3,6 \%$ & 1695 & $3,92 \%$ & 27,5 \\
\hline Сосновоборский район & 14372 & $1,1 \%$ & 1630 & $3,77 \%$ & 8,8 \\
\hline
\end{tabular}

В ходе исследования также были выделены центры кластеризации Республики Башкортостан, определены и проанализированные характеристики экономического пространства данного региона. Ключевым центром инновационной трансформации экономического пространства республики является Нефтехимический территориальный кластер Республики Башкортостан. Якорные предприятия кластера находятся в городах Уфа, Стерлитамак, Салават, Октябрьский, также предприятия кластера расположены в городах Нефтекамск, Кумертау, Ишимбай, Благовещенск, Давлеканово.

Рассмотрим характеристики экономического пространства республики, находящегося под непосредственным воздействием экстерналий кластерного развития (таблица 3). Также к территориям, находящимся под воздействием экстерналий процессов развития кластера $\mathrm{Pe}$ - спублики Башкортостан можно отнести Азнакаевский, Бавлинский, Бугульминский и Ютазинский районы Республики Татарстан, Камбарский и Сарапульский районы Республики Удмуртия, Октябрьский и Тюльганский районы Оренбургской области.

Также в состав кластера входят организации, находящиеся в других регионах страны: г Москва, г. Санкт-Петербург, Вологодская область, Воронежская область, Нижегородская область, Омская область, Оренбургская область, Республика Татарстан, Свердловская область, Тверская область, Тульская область, Челябинская область.

Ключевым центром инновационной трансформации экономического пространства Чувашской Республики является Инновационный территориальный электротехнический кластер Чувашской Республики. Якорные предприятия 
Таблица 3. Территории, территория которых относится к ядру, центру и периферии развития Нефтехимического территориального кластера

\begin{tabular}{|c|c|c|c|c|c|}
\hline Территории & $\begin{array}{c}\text { Население, } \\
\text { чел. }\end{array}$ & $\begin{array}{c}\text { Доля от } \\
\text { населения } \\
\text { региона, \% }\end{array}$ & $\begin{array}{c}\text { Площадь, } \\
\text { км}^{2}\end{array}$ & $\begin{array}{c}\text { Доля от } \\
\text { площади } \\
\text { региона, \% }\end{array}$ & 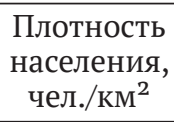 \\
\hline Республика Башкортостан, всего & 4013786 & $100,0 \%$ & 143600 & $100,00 \%$ & 28,0 \\
\hline $\begin{array}{l}\text { Экономическое пространство } \\
\text { кластера, всего }\end{array}$ & 2734168 & $68,1 \%$ & 63775 & $44,41 \%$ & 42,9 \\
\hline Ядро кластрера, всего & 1242887 & $31,0 \%$ & 809 & $0,56 \%$ & 1536,3 \\
\hline Городской округ город Уфа & 1128787 & $28,1 \%$ & 710 & $0,49 \%$ & 1589,8 \\
\hline город Октябрьский & 114100 & $2,8 \%$ & 99 & $0,07 \%$ & 1152,5 \\
\hline город Салават & 150500 & $3,7 \%$ & 106 & $0,07 \%$ & 1419,8 \\
\hline город Стерлитамак & 276394 & $6,9 \%$ & 109 & $0,08 \%$ & 2535,7 \\
\hline Центр кластера, без ядра & 725338 & $18,1 \%$ & 27100 & $18,87 \%$ & 26,8 \\
\hline Аургазинский район & 33358 & $0,8 \%$ & 2014 & $1,40 \%$ & 16,6 \\
\hline Благовещенский район & 49380 & $1,2 \%$ & 2259 & $1,57 \%$ & 21,9 \\
\hline Иглинский район & 60777 & $1,5 \%$ & 2456 & $1,71 \%$ & 24,7 \\
\hline Ишимбайский район & 88092 & $2,2 \%$ & 4003 & $2,79 \%$ & 22,0 \\
\hline Кармаскалинский район & 50319 & $1,3 \%$ & 1751 & $1,22 \%$ & 28,7 \\
\hline Кушнаренковский район & 27074 & $0,7 \%$ & 1718 & $1,20 \%$ & 15,8 \\
\hline Мелеузовский район & 84042 & $2,1 \%$ & 3201 & $2,23 \%$ & 26,3 \\
\hline Стерлитамакский район & 42281 & $1,1 \%$ & 2222 & $1,55 \%$ & 19,0 \\
\hline Туймазинский район & 132463 & $3,3 \%$ & 2362 & $1,64 \%$ & 56,1 \\
\hline Уфимский район & 87798 & $2,2 \%$ & 1597 & $1,11 \%$ & 55,0 \\
\hline Фёдоровский район & 17147 & $0,4 \%$ & 1693 & $1,18 \%$ & 10,1 \\
\hline Чишминский район & 52607 & $1,3 \%$ & 1824 & $1,27 \%$ & 28,8 \\
\hline Периферия кластера, всего & 765943 & $19,1 \%$ & 35866 & $24,98 \%$ & 21,4 \\
\hline город Агидель & 14219 & $0,4 \%$ & 66 & $0,05 \%$ & 215,4 \\
\hline город Кумертау & 59478 & $1,5 \%$ & 170 & $0,12 \%$ & 349,9 \\
\hline город Нефтекамск & 131138 & $3,3 \%$ & 147 & $0,10 \%$ & 892,1 \\
\hline Альшеевский район & 36823 & $0,9 \%$ & 2411 & $1,68 \%$ & 15,3 \\
\hline Архангельский район & 17630 & $0,4 \%$ & 2411 & $1,68 \%$ & 7,3 \\
\hline Бирский район & 64690 & $1,6 \%$ & 1717 & $1,20 \%$ & 37,7 \\
\hline Благоварский район & 25423 & $0,6 \%$ & 1688 & $1,18 \%$ & 15,1 \\
\hline Буздякский район & 27337 & $0,7 \%$ & 1633 & $1,14 \%$ & 16,7 \\
\hline Гафурийский район & 31364 & $0,8 \%$ & 3038 & $2,12 \%$ & 10,3 \\
\hline Давлекановский район & 40162 & $1,0 \%$ & 1866 & $1,30 \%$ & 21,5 \\
\hline Дюртюлинский район & 61051 & $1,5 \%$ & 1669 & $1,16 \%$ & 36,6 \\
\hline Ермекеевский район & 15737 & $0,4 \%$ & 1437 & $1,00 \%$ & 11,0 \\
\hline Калтасинский район & 23613 & $0,6 \%$ & 1519 & $1,06 \%$ & 15,5 \\
\hline Краснокамский район & 27467 & $0,7 \%$ & 1688 & $1,18 \%$ & 16,3 \\
\hline Кугарчинский район & 28649 & $0,7 \%$ & 3373 & $2,35 \%$ & 8,5 \\
\hline Куюргазинский район & 23360 & $0,6 \%$ & 2235 & $1,56 \%$ & 10,5 \\
\hline Миякинский район & 25620 & $0,6 \%$ & 2051 & $1,43 \%$ & 12,5 \\
\hline Стерлибашевский район & 18207 & $0,5 \%$ & 1609 & $1,12 \%$ & 11,3 \\
\hline Чекмагушевский район & 28546 & $0,7 \%$ & 1686 & $1,17 \%$ & 16,9 \\
\hline Шаранский район & 20518 & $0,5 \%$ & 1384 & $0,96 \%$ & 14,8 \\
\hline Янаульский район & 44911 & $1,1 \%$ & 2068 & $1,44 \%$ & 21,7 \\
\hline
\end{tabular}


кластера находятся в городе Чебоксары, также предприятия кластера расположены в следующих населённых пунктах г. Цивильск, г. Шумерля. В таблице 4 представлены данные о численности населения и площади муниципальных образований, отнесённых к центру и периферии Инновационного территориального электротехнического кластера Чувашской Республики. Также в кластер входят 2 крупных государственных университета, находящихся в столице соседней Республики Марий Эл городе Йошкар-Ола. Также к территориям, находящимся под воздействием экстерналий процессов развития Инновационного территориального электротехнического кластера Чувашской Республики можно отнести Воротынский, Пильнинский и Сеченовский районы Нижегородской области, а также Волжский, Горномарийский и Звениговский районы Республики Марий Эл.
Выводы. В ходе исследования были рассмотрены отличающиеся по площади и численности населения регионы Поволжья. На территории данных регионов расположены инновационные кластеры, также различающиеся по уровню организационного развития, количеству организаций-участников, отраслевой специализации. Был сделан вывод о существенной неравномерности распределения предприятий и организаций кластера в экономическом пространстве региона. Подчеркнём расположение ядра кластеров на территории столиц субъектов РФ, либо крупных городов, формирующих отдельные от столичной агломерации (Стерлитамак, Салават, Ишимбай). Также для Республики Башкортостан определен многоядерный характер кластеризации, когда предприятия, формирующие ядро кластера, находятся на территории четырёх городов.

Таблица 4. Муниципальные образования, территория которых относится к ядру, центру и периферии развития Инновационного территориального электротехнического кластера Чувашской Республики

\begin{tabular}{|c|c|c|c|c|c|}
\hline Территории & $\begin{array}{c}\text { Население, } \\
\text { чел. }\end{array}$ & $\begin{array}{c}\text { Доля от } \\
\text { населения } \\
\text { региона, \% }\end{array}$ & Площадь, км² & $\begin{array}{c}\text { Доля от } \\
\text { площади } \\
\text { региона, \% }\end{array}$ & $\begin{array}{c}\text { Плотность } \\
\text { населения, } \\
\text { чел./км² }\end{array}$ \\
\hline Чувашская Республика, всего & 1207875 & $100,0 \%$ & 18300 & $100,00 \%$ & 66,0 \\
\hline $\begin{array}{l}\text { Экономическое пространство } \\
\text { кластера, всего }\end{array}$ & 1083868 & $89,7 \%$ & 13224 & $72,26 \%$ & 82,0 \\
\hline Ядро кластрера, всего & 626434 & $51,9 \%$ & 299 & $1,63 \%$ & 2095,1 \\
\hline Чебоксары & 500052 & $41,4 \%$ & 248 & $1,36 \%$ & 2016,3 \\
\hline Новочебоксарск & 126382 & $10,5 \%$ & 51 & $0,28 \%$ & 2478,1 \\
\hline Центр кластера, без ядра & 207011 & $17,1 \%$ & 5260 & $28,74 \%$ & 39,4 \\
\hline Аликовский район & 15882 & $1,3 \%$ & 554 & $3,03 \%$ & 28,7 \\
\hline Красноармейский й район & 14279 & $1,2 \%$ & 456 & $2,49 \%$ & 31,3 \\
\hline Мариинско-Посадский район & 22411 & $1,9 \%$ & 686 & $3,75 \%$ & 32,7 \\
\hline Моргаушский район & 33009 & $2,7 \%$ & 845 & $4,62 \%$ & 39,1 \\
\hline Урмарский район & 22992 & $1,9 \%$ & 598 & $3,27 \%$ & 38,4 \\
\hline Цивильский район & 36023 & $3,0 \%$ & 790 & $4,32 \%$ & 45,6 \\
\hline Чебоксарский район & 62415 & $5,2 \%$ & 1331 & $7,27 \%$ & 46,9 \\
\hline Периферия кластера, всего & 250423 & $20,7 \%$ & 7665 & $41,89 \%$ & 32,7 \\
\hline город Канаш & 44795 & $3,7 \%$ & 18 & $0,10 \%$ & 2488,6 \\
\hline город Шумерля & 28356 & $2,3 \%$ & 13 & $0,07 \%$ & 2181,2 \\
\hline Вурнарский район & 32221 & $2,7 \%$ & 1012 & $5,53 \%$ & 31,8 \\
\hline Ибресинский район & 23519 & $1,9 \%$ & 1201 & $6,56 \%$ & 19,6 \\
\hline Козловкий район & 19273 & $1,6 \%$ & 516 & $2,82 \%$ & 37,4 \\
\hline Комсомольский район & 25217 & $2,1 \%$ & 630 & $3,44 \%$ & 40,0 \\
\hline Красночетайский район & 14426 & $1,2 \%$ & 691 & $3,78 \%$ & 20,9 \\
\hline Порецкий район & 12606 & $1,0 \%$ & 1116 & $6,10 \%$ & 11,3 \\
\hline Шумерлинский район & 9127 & $0,8 \%$ & 1047 & $5,72 \%$ & 8,7 \\
\hline Ядринский район & 26065 & $2,2 \%$ & 897 & $4,90 \%$ & 29,1 \\
\hline Янтиковский район & 14818 & $1,2 \%$ & 524 & $2,86 \%$ & 28,3 \\
\hline
\end{tabular}




\section{Библиографический список}

1. Fujita, M., Krugman P., Venables A.J.The Spatial Economy: Cities, Regions, and International Trade.- Cambridge, Massachusetts: The MIT Press, 1999. - 367 p.

2. Ketels, C.H. 2013, Cluster policy: A guide to the state of the debate. In: Meusburger, P. Glückler, J., el Meskioui, M. (eds.) Knowledge and the economy, Dordrecht, Springer, p. 249-269

3. Lindqvist, G. Disentangling Clusters: Agglomeration and Proximity Effects / G. Lindqvist. - Stockholm: EFI, 2009.$314 \mathrm{p}$.

4. Porter, M.E., Ketels, C.H. 2009, Clusters and industrial districts: Common roots, different perspectives. In: Becattini, G., Bellandi, M., de Propis, L. (eds.) A handbook of industrial districts, Cheltenham, Edward Elgar, p. 172-183

5. Анимица, П.Е.Становление бизнес-территорий в контексте концепций саморазвития региона / П.Е. Анимица //Региональная экономика: теория и практика. -2011. - № 46 (229) - С. 20-24

6. Лейзерович, Е.Е. Об основных экономических районах (макрорайонах) России / Е.Е. Лайзерович // Региональные исследования. - 2014. - № 3- С. 4-11

7. Полякова, А.Г. Региональное экономическое пространство и территориальное развитие: оценка действия сил связности /А.Г. Полякова, И. С. Симарова // Вестн. УрФУ. Серия экономика и управление. - 2014. - № 2 C. $48-60$

8. Полян, П. М. Территориальные структуры - урбанизация - расселение: теоретические подходы и методы изучения/ Предисловия: Г. М. Лаппо и А.И. Трейвиша. М.: Новый хронограф, 2014. - 715 с.

9. Российская кластерная обсерватория [Электронный ресурс].- Режим доступа: https://cluster.hse.ru/ (дата обращения: 23.03.2021)

10. Фальцман, В. Россия. Экономический рост в новой геополитической обстановке. Реальность и надежды/ Фальщман В. // Современная Европа. - 2015.- № 1.- С. 79-92. 